\title{
Effect of chemical treatments on the mechanical properties of technical flax fibres with emphasis on stiffness improvement.
}

\author{
D. Perremans ${ }^{a *}$, K. Hendrickx ${ }^{a}$, I. Verpoest ${ }^{a}$, A.W. Van Vuure ${ }^{a}$ \\ aDepartment of Materials Engineering, KU Leuven, Kasteelpark Arenberg 44 bus 2450, 3001 \\ Heverlee, Belgium \\ ${ }^{*}$ Corresponding author. Tel. +3216321231; E-mail address: \\ dieter.perremans@mtm.kuleuven.be
}

\section{ABSTRACT}

The weak visco-elastic interphase between elementary fibers in a reinforcing technical flax fiber is presumed to play a crucial role in the stiffness reduction during loading. To avoid this stiffness reduction, ethanedial (glyoxal), 3-aminopropyltriethoxysilane (APS) and dimethyloldihydroxyethylene urea (DMDHEU) were investigated as potential fiber treatments in this paper. Tensile tests on single technical fibers show that treating the fibers in an aqueous $3 \mathrm{wt} \%$ glyoxal solution was sufficient to increase the technical fiber modulus from $41.6 \pm 2.3 \mathrm{GPa}$ to $57.3 \pm 2.9 \mathrm{GPa}$. Further, spectroscopic techniques (FTIR, NMR and XPS) detected increased amounts of acetal and ester bonds after glyoxal treatment. This suggests that cross-linking has taken place between pectin and hemicellulose molecules in the amorphous interphase between elementary fibres. APS and DMDHEU treatments were less successful in improving the technical fibre stiffness due to their lower reactivity towards hydroxyl functionalities compared to glyoxal. 


\section{Introduction}

Composite materials offer the advantage of being lightweight while preserving high stiffness and strength. Traditional reinforcing phases, such as glass, carbon and aramid fibers now enjoy general market acceptance and are increasingly used in aviation, automotive and construction industry. However, as recycling legislation is tightening, the demand for alternative reinforcing phases and recovery processes continues to rise. Moreover, the embodied energy of traditional materials and synthetic fibre composites is rather high, as visible in table 1. Natural fiber composites can provide an elegant solution to these problems.

Despite being low cost, having a 'green' image and excellent mechanical properties, it is not easy for natural fibers such as flax to conquer a solid position in the field of composites. Though it has recently been proven that, when measured correctly through impregnated fibre bundle testing, the scatter in mechanical properties of flax fibres (from a single batch) is in line with that of glass fibres, the negative image that natural fibre composites are subject to large variations in their mechanical properties is often applied as (an incorrect) argument for the refrainment of their usage [1]. The limitation of their processing temperatures and their moisture susceptibility alternatively form bottlenecks for their application, despite tremendous progress over the recent decades [2-7]. Finally, the lack of knowledge about the relationship between the fiber's composition, its microstructure and its mechanical performance hinders substantial improvements from a fundamental level [8-10]. 
Table 1: Embodied energy of a $1 \times 1 \mathrm{~m}^{2}$ façade panel with variable thickness to correspond to equivalent mechanical performance as a brick panel. Volume fractions of glass and hemp are estimated at $40 \%$. Other details can be found in [11]. A natural fibre composite system results in an embodied energy reduction by a factor 8 .

\begin{tabular}{|c|c|c|}
\hline Material & Embodied energy per unit mass (MJ/Kg) & Embodied energy (MJ) \\
\hline Bricks & 8 & 1968 \\
\hline Aluminium & 218 & 1177 \\
\hline Glass/polyester & 100 & 540 \\
\hline Hemp/polyester & 69 & 249 \\
\hline
\end{tabular}

Table 2 lists the average overall chemical composition of a selection of vegetable fibres [12-14]. Cellulose, hemicellulose, pectin and lignin can be identified as the major constituents of the chemical composition of vegetable fibres. Their amount and interaction determine the harvesting conditions as well as their mechanical behavior. Flax fibres belong to the class of vegetable fibres with high cellulose content and moderate amounts of polyosic substances such as hemicellulose and pectin. A cellulose content between 60 and $80 \mathrm{wt} \%$ is obtained in most studies. The high molecular weight and crystallinity of cellulose (polymerization degree over 10000) contribute to the excellent mechanical properties of flax fibres [15]. Moreover, the crystalline structure is highly chemically stabilized as a result of the inter- and intramolecular formation of hydrogen bonds between the hydroxyl groups of the cellulose polymer [16]. 
Hemicellulose and pectins comprise the non-cellulosic, non-linear polysaccharides [1718]. Because of their branched structure, their degree of polymerization is significantly reduced; common values reported in literature situate around 150-200 [18]. Their open structure and availability of polar groups make hemicellulose and pectin susceptible for chemical degradation [19]. Nevertheless, hemicellulose and pectin are important as linking agents between the cellulose microfibrils and are, from a mechanical point of view, therefore responsible for the stress transfer between these cellulose microfibrils.

Table 2: Average chemical composition of a selection of natural fibres in wt\% [12-14].

\begin{tabular}{|c|c|c|c|c|c|}
\hline Fibre & Cellulose & Hemicellulose & Pectin & Lignin & Waxes \\
\hline Hemp & 76.1 & 12.3 & n.a. & 5.7 & n.a. \\
\hline Jute & 64.4 & 12.0 & 0.2 & 11.8 & 0.5 \\
\hline Coir & $32-43$ & $<1$ & n.a. & $40-45$ & n.a. \\
\hline Flax & 71.0 & 16.7 & 1.8 & 2.0 & 1.5 \\
\hline Cotton & 82.7 & 5.7 & 5.7 & n.a. & 0.6 \\
& & & & & \\
\hline
\end{tabular}

Figure 1 reflects the typical microstructure going from the flax stem to the lamella of the thick secondary wall. After retting, breaking and scutching, the flax fibre bundles are separated from the stem. These fibre bundles (technical fibres) have an apparent diameter of $100-200 \mu \mathrm{m}$ and are a cluster of elementary fibres that are held together by a pectic cement [20]. This pectin-rich interphase is referred to as middle lamella. 
Recent research established that the middle lamella plays a vital role in the behavior of technical flax fibres during loading and deformation [21]. The elementary fibres possess diameters around $10-40 \mu \mathrm{m}$ depending on the growth conditions of the plant [22-23]. They consist of two cell types: an outer primary and an inner secondary cell wall. The secondary cell wall can be divided into 3 concentric sections which differ in terms of structure and thickness [20]. The S2 layer comprises around $80 \%$ of the cell's cross-section and therefore largely determines the mechanical behavior of the elementary fibre [24]. At a nanoscopic scale the cell walls consist of lamellae measuring a few nanometers in thickness. In these lamellae cellulosic microfibrils are embedded in an amorphous matrix of hemicellulose and pectin [25-27]. In the bulk S2 cell wall the microfibrils in flax are tilted $10^{\circ}$ to the fiber axis [28, 29]. The stiffness of the cellulose microfibrils is determined to be $137 \mathrm{GPa}$ [30].
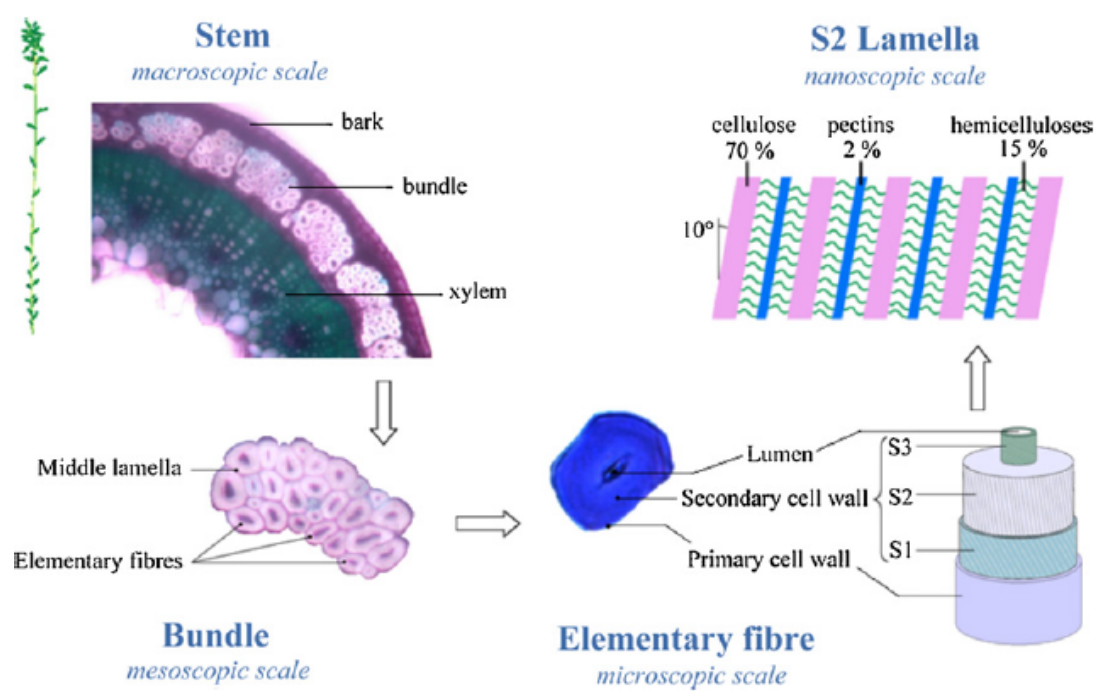

Figure 1: Cross-sections and schematics of flax at different scales. The fibre bundle is composed of a series of multi-layered elementary fibres that are glued together by a pectin-rich interphase, the middle lamella [20] 
The tensile properties of elementary flax fibers have been studied extensively. Common values reported in literature for the tensile strength range from 600 to 2000 $\mathrm{MPa}$, with the Young's modulus varying from 60 to $80 \mathrm{GPa}$. The strain to failure is limited to around 1.5 to $2 \%$, with the large scatter is in part attributed to incorrect measurement protocols $[25,28,31-32]$. It has further been established that elementary fibres seem to exhibit a tri-linear behavior in their stress-strain curves [25, 33]. However, conclusive and quantitative evidence as for the exact deformation mechanism is still lacking. Most authors seem to think that the apparent stiffness decrease around $0.3 \%$ strain is attributed to a visco-elastic shearing of the amorphous components. The recovery is mostly linked to an induced crystallization of amorphous cellulose components and to a microfibril alignment with the loading axis [25, 33-34].

Contrary to expectations, the tensile behavior of technical flax fibre is less documented. The tensile strength is reported around 300-600 MPa, the decrease linked to higher defect probability as a result of higher span length [35-36]. Reported mean values for the Young's modulus are as well surprisingly lower, ranging from 30$37 \mathrm{GPa}$, with a strain-to-failure that barely surpasses $1.4 \%$ [35-37]. This value is significantly lower than the stiffness reported from back-calculation of data from impregnated fibre bundle tests on technical fibres [1]. The exact reason why the apparent stiffness is higher for impregnated technical fibres is still unknown, though it is assumed that the deformation behavior of the interphase between elementary fibres will play a critical role. 
This paper therefore will further focus on the apparent stiffness anomaly between technical flax fibres, as well as investigate whether the use of chemical treatments can increase the stiffness during loading of technical flax fibres. In particular, cross-linking of the amorphous components in between the cellulose micro-fibrils and in the middle lamellae will be targeted.

\section{Materials and methods}

\subsection{Materials}

The fibers used in the experiments are long, hackled flax fibers in the form of UD-layers supplied by Lineo NV (FlaxTape R200). The areal density of these layers or tapes is 200 $\mathrm{g} / \mathrm{m}^{2}$

\subsection{Methods}

\subsubsection{Fibre treatments}

To improve the stiffness of the flax fibres, treatments aiming to cross-link the components in the middle lamellae (hemicellulose, pectins,..) with high diffusivity monomers are aspired to. The selected monomers include ethanedial (glyoxal), 3aminopropyltriethoxysilane (APS) and dimethyloldihydroxyethylene urea (DMDHEU). All the proposed chemical treatments are executed in aqueous solutions at room temperature for a fixed amount of time. An overview of the different treatment conditions is given in table 3 . 
Prior to testing, the fibres are stored in an equilibrated room (relative humidity of $50 \pm 3 \%$, room temperature) until saturation following ASTM D5229/D5229M - 92. In addition to the potential cross-linking treatments, a pre-treatment with $(2,2,6,6-$ tetramethylpiperidin-1-yl)oxidanyl (TEMPO), to expose the functional groups of the fibre, is also evaluated. For this, the fibres are submerged in an aqueous $1.5 \mathrm{~g} / \mathrm{L}$ TEMPO solution. $\mathrm{NaBr}$ is dissolved in a $10: 1 \mathrm{wt} \%$ ratio compared to TEMPO. $\mathrm{NaOCl}$ is added until the molar ratio of $\mathrm{NaOCl}$ to cellulose equals 0.5 . Finally, a fixed $\mathrm{pH}$ value of 10 is guaranteed by the timely addition of a $0.5 \mathrm{M} \mathrm{NaOH}$ solution. The reaction is allowed to proceed for $1 \mathrm{~h}$ after which the addition of $1 \mathrm{~mL}$ of methanol terminates the reaction and the $\mathrm{pH}$ is adjusted to 7 with $\mathrm{HCl}$.

Table 3: Overview of the potential stiffness altering treatment conditions

\begin{tabular}{|c|c|c|c|c|c|}
\hline Treatment & Concentration & catalyst & $\begin{array}{c}\text { Immersion } \\
\text { time }\end{array}$ & $\begin{array}{c}\text { Curing } \\
\text { temperature }\end{array}$ & $\begin{array}{r}\text { Curing } \\
\text { time }\end{array}$ \\
\hline Ethanedial (glyoxal) & 3 and $15 w t \%$ & $\begin{array}{c}0.04 \text { mol ratio } \\
\mathrm{Al}_{2}\left(\mathrm{SO}_{4}\right)_{3} . \\
18 \mathrm{H}_{2} \mathrm{O}\end{array}$ & $10 \mathrm{~min}$ & $160^{\circ} \mathrm{C}$ & $10 \mathrm{~min}$ \\
\hline $\begin{array}{l}\text { 3-aminopropyl- } \\
\text { triethoxysilane (APS) }\end{array}$ & 10vol\% & / & $10 \mathrm{~min}$ & $90^{\circ} \mathrm{C}$ & $1 \mathrm{~h}$ \\
\hline $\begin{array}{l}\text { Dimethyloldihydroxy- } \\
\text { ethylene urea (DMDHEU) }\end{array}$ & $20 w t \%$ & / & $10 \mathrm{~min}$ & $160^{\circ} \mathrm{C}$ & $10 \mathrm{~min}$ \\
\hline
\end{tabular}




\subsubsection{Testing}

\subsubsection{Tensile testing}

Single, technical flax fibers were tested in tension using an Instron 5943 with a load cell of $100 \mathrm{~N}$ until failure occurred, following the ASTM C1557-03 standard. The span length was set to $50 \mathrm{~mm}$. The cross-head displacement velocity equaled $0.25 \mathrm{~mm} / \mathrm{min}$. A LIMESS optical strain measurement tracked the elongation of the fibres. The sampling rate was set at 2 images per second. The recorded images were post-processed with the digital image correlation software VIC 2D. Two small white dots at a distance of approximately $5 \mathrm{~mm}$ were finely applied on the fibre prior to testing. To compare the sample means of two separate data sets, an independent, two-sided student's t-test was used with a significance level of 0.05 . The variances of the data sets were assumed equal only if they passed the F-test for the equality of variances.

\subsubsection{Fourier transform infrared spectroscopy (FTIR)}

Treated, pre-treated and untreated flax fibres are ground and thinly dispersed to a powder form. 1 to $2 \mathrm{mg}$ of the compound is homogenously mixed with $50-100 \mathrm{mg}$ of $\mathrm{KBr}$ powder. The mixture is pressed at $138 \mathrm{MPa}$ under vacuum to form a pellet sample. Multi-frequency radiation is used to irradiate the sample. Using the fast Fourier transform algorithm the raw absorption data are converted to the actual spectrum. In this work, a Bruker IFS 66v/S infrared spectrometer operating under vacuum was used. For each sample the absorption spectrum was determined between wavenumbers 400 $\mathrm{cm}^{-1}$ and $4000 \mathrm{~cm}^{-1}$. 


\subsubsection{X-ray photo-electron spectroscopy (XPS)}

XPS measurements are carried out to identify the elemental composition and the bond formation of surface molecules of treated, untreated and pre-treated technical flax fibres. In this work, a Surface Science Instruments SSX 100/206 spectrometer using a monochromatized and micro-focused AlKa X-ray beam was used to acquire the spectra.

\subsubsection{Nuclear magnetic resonance (NMR)}

Solid state nuclear magnetic resonance is applied to determine the chemical environment of an irradiated carbon atom. A Bruker AMX400 (7.0 T) was used to measure the ${ }^{13} \mathrm{C}$ NMR spectrum of finely ground flax powder. Cross polarization and magic angle spinning was used to enhance the spectrum. In total 382 scans were accumulated with a recycle delay of $10 \mathrm{~s}$. Contact time was $1 \mathrm{~ms}$. Samples were pressed in $4 \mathrm{~mm}$ rotors, spinning at a frequency of $6 \mathrm{kHz}$ in the spectrometer. Data analysis and deconvolution were carried out with the dmfit software.

\subsubsection{Statistical testing}

Statistical testing was performed using a two-sided student-t distribution. The variance equality is for each experiment tested trough a fischer test. The degrees of freedom 't(v)' and probability significance ' $p$ ' will be given for each experimental set-up. 


\section{Results and discussion}

\subsection{Tensile tests}

The results of the technical fiber tensile tests, listed in table 4 and summarized in figures 2 and 3, indicate strong variations in the treatment effect. First, it is noted that the initial modulus of the single technical fibers is not altered by the APS or DMDHEU treatments compared to the untreated fibers, in contrast to glyoxal which appears to significantly stiffen the fibers $\left(t(v)=23, p<10^{-5}\right)$. Figure $2 b$ shows that only after the glyoxal and APS treatments the strength of the fibers is increased. Furthermore, the failure strain of the fibers is apparently decreased by the glyoxal treatment. When the stiffness of the untreated technical fibers ( 40GPa) is compared to literature data on elementary fibers, yielding a modulus close to $60 \mathrm{GPa}$, the difference is significant $[25,28]$.

Table 4: Longitudinal tensile modulus, strength and strain-to-failure of untreated and treated single technical flax fibres.

\begin{tabular}{|c|c|c|c|}
\hline Treatment & $\begin{array}{c}\text { Tensile modulus } \\
(\mathrm{GPa})\end{array}$ & $\begin{array}{c}\text { Ultimate tensile strength } \\
(\mathrm{MPa})\end{array}$ & $\begin{array}{c}\text { Tensile strain-to-failure } \\
\text { (\%) }\end{array}$ \\
\hline Untreated & $41.6 \pm 2.3$ & $457 \pm 94$ & $1.59 \pm 0.35$ \\
\hline Glyoxal 3 & $57.3 \pm 2.9$ & $635.1 \pm 99.4$ & $1.17 \pm 0.20$ \\
wt\% & & & $1.42 \pm 0.3$ \\
\hline APS & $41.8 \pm 3.5$ & $587.8 \pm 105.1$ & $1.33 \pm 0.39$ \\
\hline DMDHEU & $37.7 \pm 3.0$ & $454.7 \pm 147.9$ & \\
\hline
\end{tabular}




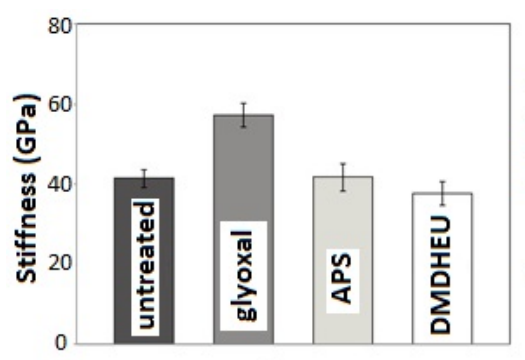

(a)

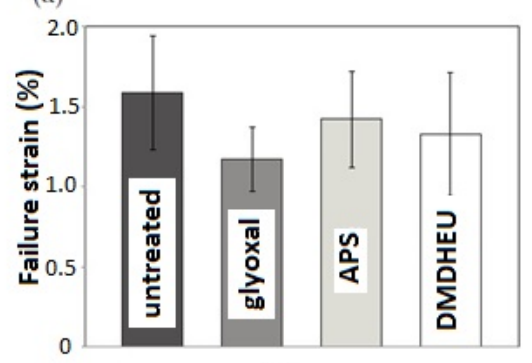

(c)

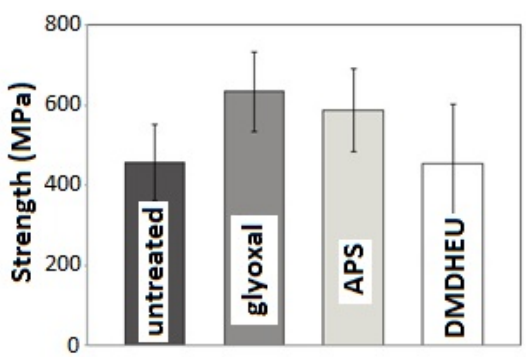

(b)

Figure 2: (a) Modulus of untreated and treated single technical flax fibres. (b) Strength of untreated and treated single technical flax fibres. (c) Failure strain of untreated and treated single technical flax fibres.

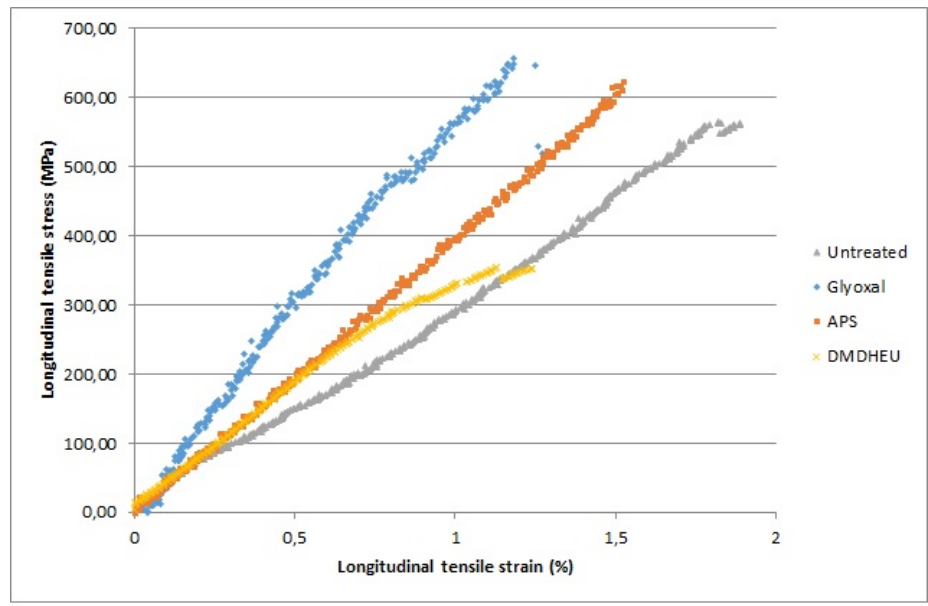

Figure 3: Typical longitudinal tensile stress-strain curves of individual treated and untreated technical flax fibres. The observed slight differences with the registered strength values in table 2 are of statistical scatter nature. 
A possible explanation for the difference in stiffness between technical and elementary fibres could be that increased moisture diffusion leads to the scission of hydrogen bonds between polyosic molecules (pectin, hemicellulose) in the cell wall or in the amorphous interphase between elementary fibers. The presumed increase in moisture absorption would stem from the larger presence and accessibility of hydrophilic components, primarily in the pectin-rich middle lamellae. This would enhance the mobility of the molecules and therefore decrease the technical fibre stiffness relative to the elementary one.

Following this theory, instantaneous testing after drying should lead to higher technical fibre stiffness values. It was found that this procedure raised the average stiffness of the fibers from $41.5 \mathrm{GPa}$ to $43.2 \mathrm{GPa}$, but this was proven to be insignificant $(t(v)=25, p=0.59)$. Clearly, the relative humidity of the environment does not dominate the apparent stiffness difference between technical and elementary fibres.

The main difference between technical and elementary fibres lies in the presence of the amorphous, pectin-rich middle lamellae. This interphase has been proven to possess very low mechanical properties [21]. Upon deformation, the force transfer between elementary fibres has to occur through this weak interphase. It is therefore assumed that a shearing deformation of this interphase leads to relative sliding of the elementary fibres compared to one another. This relative sliding of the elementary fibres and shearing behaviour of the middle lamellae would assist the applied deformation resulting in an apparent decrease in stiffness. 
This phenomenon would hardly be noticed in impregnated fibre bundle tests as the reinforcing technical fibres are mostly only 2-3 elementary fibres thick. During deformation of the impregnated fibre bundles, most of the elementary fibres are therefore bound to the resin. This will limit their relative sliding capabilities. The weak interphase strength that exists between the elementary fibres is still present, but its influence as a stress transfer medium is severely reduced.

The increase in the fiber stiffness after glyoxal treatment may indicate that the polyosic interphase between elementary fibres has stiffened as a result of a crosslinking reaction. The proposed reaction mechanism is elaborated in figure 4 . The dialdehyde is first hydrolyzed to a metastable polyol through a nucleophilic addition reaction in acid environment. Then, protonation of the hydroxyl group results in the elimination of water and the formation of the intermediate, unstable oxonium ion. Finally, the oxonium ion reacts with the alcohol functionalities of the pectins or hemicelluloses through a nucleophilic addition in acid environment. Given that water is a better leaving group than the newly formed ether links, the reaction is driven to eliminate the remaining hydroxyl groups of the hemiacetal, converting the hemiacetal to an acetal. 

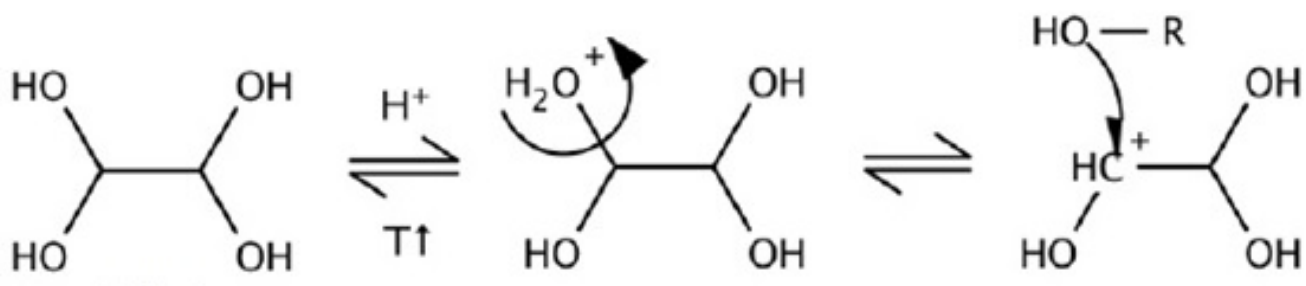

aldehyde
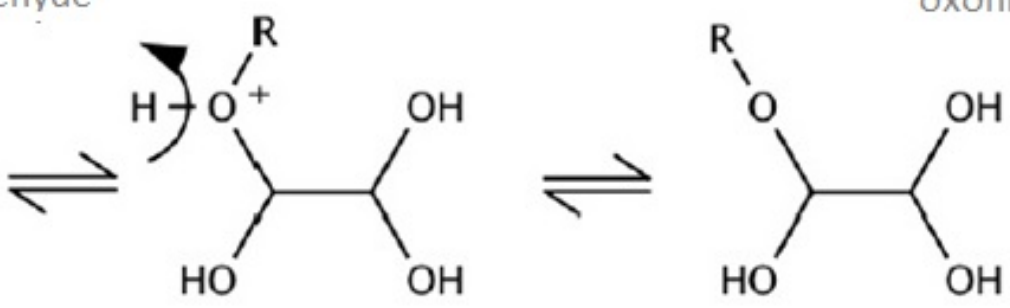

hemi-acetal

Figure 4: Reaction mechanism between glyoxal and an alcohol. The $\mathrm{R}-\mathrm{OH}$ group refers to the polyosic alcohol functionality. The starting point already shows the hydrolyzed aldehyde. The end product is a hemi-acetal. By further reaction of the remaining hydroxyl groups in a similar manner, the cross-linking acetal bonds are formed.

The reason why APS and DMDHEU fail to increase stiffness is due to their decreased reactivity towards alcohols as compared to aldehydes. A hydrolyzed APS molecule can theoretically react with three hydroxyl groups of a polyosic molecule through nucleophilic addition reactions. However, secondary and tertiary ether formation is unlikely due to the spatial arrangement of hydroxyl groups of pectins/hemicelluloses. To cross-link effectively, the amine functionality requires the presence of carboxylic acids in the amorphous network. The amount of carboxyl groups may vary somewhat but is generally speaking low compared to the amount of hydroxyl groups [39-40]. This could imply that the amount of crosslinks between polyosic molecules will be too limited to provide significant stiffening of the interphase. 
The reaction between methylol functionalities of DMDHEU and the alcohol entities of the polyosic molecules requires an elimination of the former in acid environment. It is hypothesized that the autoprotolytic character of $\mathrm{H}_{2} \mathrm{O}$ is insufficient to eliminate the methylol group.

The significant increase in tensile strength $(t(v)=23, p=1.71 \times 10-4)$ and decrease in failure strain $(t(v)=23, p=1.23 \times 10-3)$ after glyoxal treatment are further indications that additional cross-links in the interphase between elementary fibres have limited the extent of plastic deformation of the interphase.

\subsection{FTIR spectroscopy}

Figure 5 shows the FTIR spectra of untreated, treated and pre-treated flax fibres. Only relative differences in the spectrum are highlighted. The characteristic spectrum of untreated flax fibers incorporates four specific features that are in line with literature [41]. The first one includes the broad band situated around $3400 \mathrm{~cm}^{-1}$, which is attributed to the stretching of hydrogen bonded hydroxyl groups. Secondly, the two peaks occurring at $2924 \mathrm{~cm}^{-1}$ and $2873 \mathrm{~cm}^{-1}$ are the result of $\mathrm{C}-\mathrm{H}$ stretching. Further, the region between $2800 \mathrm{~cm}^{-1}$ and $1800 \mathrm{~cm}^{-1}$, indicatory of hetero-atom bonds, shows no absorption peaks. Finally, at $1732 \mathrm{~cm}^{-1}$ and $1635 \mathrm{~cm}^{-1}$ two $\mathrm{C}=\mathrm{O}$ stretching peaks are visible. The first peak is attributed to carbonyl groups incorporated in an ester function whereas the second peak reveals the existence of carboxylic acids.

The infrared spectrum of flax fibers treated with a 3 wt\% glyoxal solution does not show additional absorption peaks as compared to the spectrum of the untreated material. This is not surprising considering the low concentration and the cross-linking 
mechanism of glyoxal. The induced formation of $\mathrm{C}-\mathrm{O}$ bonds in the thin interphase between elementary fibres would be negligible compared to the ether functions that are already present in the $ß-1,4$ D-glucose units of cellulose. The functional groups induced by the reaction simply overlap with those of the flax fibers' intrinsic structure. However, increasing the concentration to $15 \mathrm{wt} \%$ does institute a change in the absorption spectrum. The peak at $1261 \mathrm{~cm}^{-1}$ is increased in intensity. This wavenumber corresponds to the stretching vibrational mode of the $\mathrm{C}-\mathrm{O}$ bond of ethers. Despite the abundance of ether bonds in cellulose chains, the ether crosslinks from the glyoxal treatment become visible in the FTIR spectrum. This confirms the mechanism that a substantial amount of ether bonds must have been formed by the reaction between glyoxal and hydroxyl entities.

The spectrum of the APS treated fibers shows two remarkable features. The carboxylic acid peak has apparently shifted downwards to $1576 \mathrm{~cm}^{-1}$. This apparent shift is presumably linked to the inability of the processing software to deconvolute two peaks that are nearly overlapping, i.e. the carboxylic acid peak and a secondary amide peak. The amide peak is the result of the reaction between the amine functionality of APS and a carboxylic acid or ester group. The latter is further supported by the diminution of the carboxylic ester peak around $1732 \mathrm{~cm}^{-1}$. The extent of this reaction is presumed to be rather limited though, as the tensile test results revealed no noticeable effect on the mechanical performance. Secondly, the peak around $3200 \mathrm{~cm}^{-1}$ is broadened. This indicates that the amount of hydrogen bonded hydroxyl functionalities is increased as a result of the interaction with the amine functionality of APS. In most circumstances, the occurrence of the Si-O stretching peak present in silanes provides further evidence 
of the APS reaction. Unfortunately, in this case it overlaps with the $\mathrm{C}-\mathrm{C}, \mathrm{C}-\mathrm{H}$ and $\mathrm{C}-\mathrm{OH}$ ring breathing and stretching vibrations located in the region between $1200 \mathrm{~cm}^{-1}$ and $850 \mathrm{~cm}^{-1}$.

The FTIR spectrum of the TEMPO pre-treated flax fibres indicates a strong increase in intensity of the carboxylic acid peak at $1576 \mathrm{~cm}^{-1}$. This supports the theory that TEMPO converts hydroxyl groups into more reactive carboxyl functionalities. This feature could be exploited to improve cross-linking in subsequent treatments with for instance diamines. However, the downside of the pre-treatment is that it does not discriminate between hydroxyl groups of cellulose, hemicellulose or pectins. Effective cross-linking can therefore occur at any level.

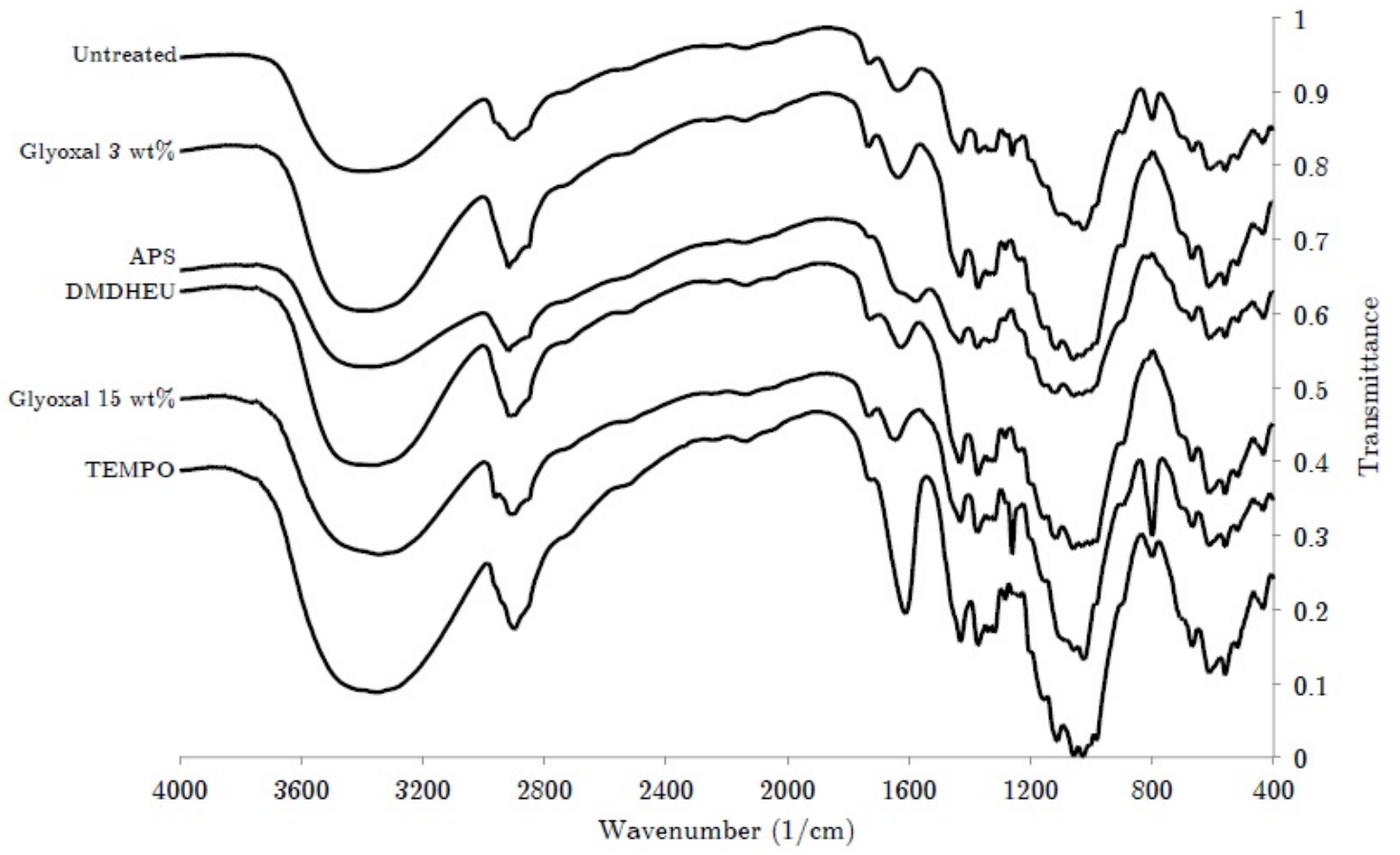

Figure 5: FTIR spectra of treated, untreated and pre-treated flax fibres. Only relative position differences may be examined. 


\subsection{NMR spectroscopy}

Nuclear magnetic resonance differs from FTIR in the sense that it has a much higher sensitivity for the surroundings of the carbon atoms. To differentiate the acetal bonds from the ester functionalities, ${ }^{13} \mathrm{C}$ NMR has been performed on untreated and glyoxal treated fibres. The NMR spectra of the untreated and treated fibers are shown in figure 6.

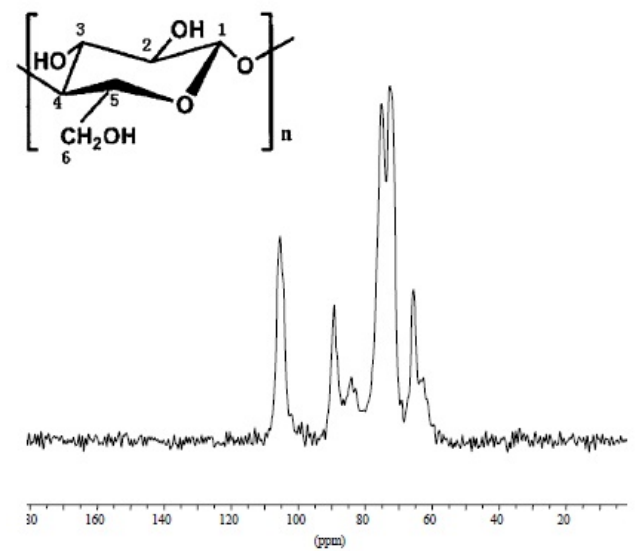

(a)

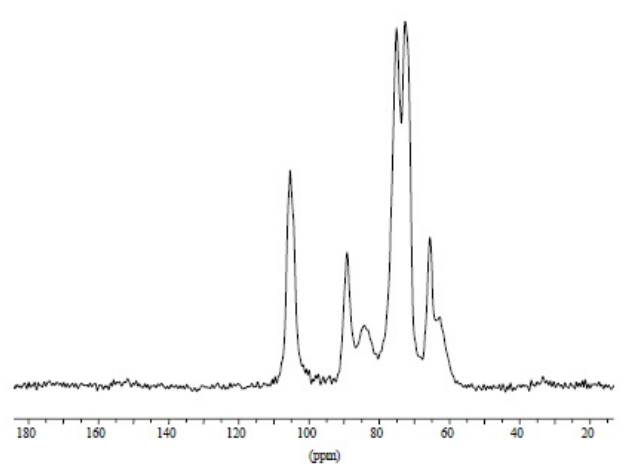

(c)

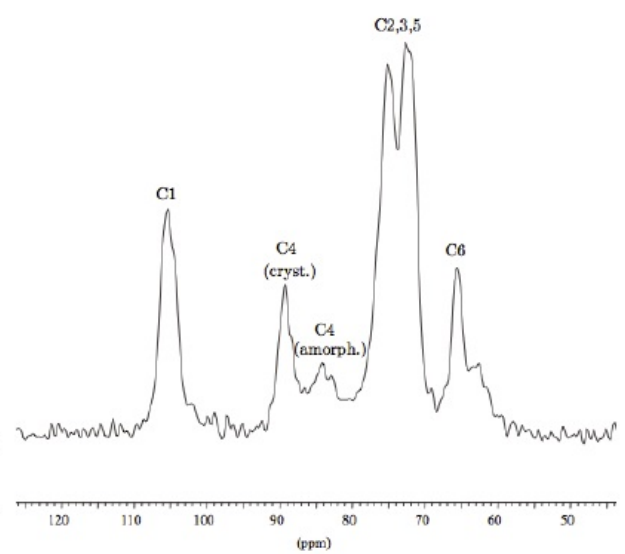

(b)

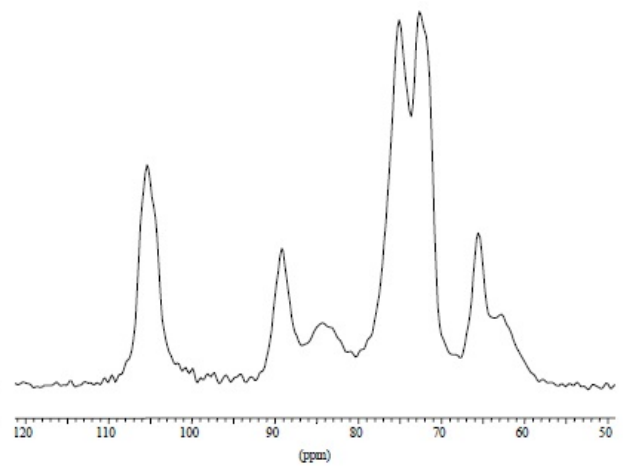

(d)

Figure 6: The 13C NMR spectra of (a), (b) untreated flax fibres, (c), (d) glyoxal 15wt\% treated flax fibres. The latter spectrum was acquired using 2000 scans instead of 600 to improve the signal-to-noise ratio. The numbering order of carbon atoms of glucose is also given. 
The main peaks are all attributed to the cellulose backbone of the fibre. The first peak, which appears at $105.2 \mathrm{ppm}$, is attributed to the $\mathrm{C} 1$ atom. At 84.0 and $89.2 \mathrm{ppm}$, the C4 atom peaks appear. The first one is due to the crystalline portion of cellulose in the fiber and the second one is the result of overlapping resonances from amorphous cellulose, hemicellulose and pectin. Further, at 75.1 and $72.3 \mathrm{ppm}$, there is a clustering of C2, C3 and C5 resonance peaks. Finally, the C6 peak appears at 65.8 ppm [29]. The NMR spectra of the treated and untreated flax fibers appear to show no significant differences. The carboxyl moiety present in pectin and hemicellulose should produce a peak around $174 \mathrm{ppm}$, but it is absent in the spectrum. Also, no sign of carbon atoms involved in ester bonds is seen. This peak should be situated around $21 \mathrm{ppm}$. Presumably, the mass fraction of amorphous substances is too low to identify their presence.

There is, however, one parameter that can be deduced from the NMR spectra. The areal ratio of the crystalline and amorphous $\mathrm{C}_{4}$ peak is a measure for the degree of crystallinity [41]. From the spectrum, it is clear that this ratio, as expected, remains unchanged after the treatment with glyoxal.

\subsection{XPS spectroscopy}

The surface composition, deduced from XPS spectroscopy, is given in table 5 for treated and untreated flax fibres. All the treatments increase the amount of oxygen atoms at the surface. This is not surprising since all treatment chemicals contain oxygen atoms in their molecular structure. Moreover, glyoxal, APS and DMDHEU 
treatments further increase the amount of $\mathrm{C}-\mathrm{O}-\mathrm{C}$ (ether), $\mathrm{O}-\mathrm{C}=\mathrm{O}$ (ester) and $\mathrm{O}-\mathrm{C}-\mathrm{O}$ (acetal) or $\mathrm{C}=\mathrm{O}$ (carbonyl) functionalities to some extent.

However, the increase in the amount of oxygen atoms at the surface appears most significant for the glyoxal treatment. This can be caused by two separate phenomena: Some residual, unreacted glyoxal remained on the surface of the fibers after the treatment, or glyoxal reacted, at least partially, with the surface of the fiber. Considering the first hypothesis, only an increase in $\mathrm{C}=\mathrm{O}$ groups would be expected, as the spectrometer operates under high vacuum $\left(<10^{-9} \mathrm{mbar}\right)$ leading to dehydration of the glyoxal. The significant increase in $\mathrm{O}-\mathrm{C}=\mathrm{O}$ bonds, attributed to a partial glyoxal reaction (one aldehyde did not react), is within that hypothesis unexplainable. Therefore, it is concluded that glyoxal reacted both partially to form esters and fully to form acetals with the surface entities of the flax fibres.

Table 5: Mole percentages of the surface atoms.

\begin{tabular}{|c|c|c|c|c|c|c|c|c|c|c|}
\hline \multirow{2}{*}{ Treatment } & \multicolumn{5}{|c|}{$\mathrm{C}_{1 \mathrm{~s}}$} & & & & & \\
\hline & C-C & $C-(O, N)$ & $\mathrm{O}-\mathrm{C}-\mathrm{O}$ & $\mathrm{O}-\mathrm{C}=\mathrm{O}$ & TOTAL & $\mathrm{O}_{1 \mathrm{~s}}$ & $\mathrm{~N}_{1 \mathrm{~s}}$ & Si-O-C & $\mathrm{Ca}_{2 p}$ & $\mathbf{P}_{2 p}$ \\
\hline Untreated & 60.5 & 18.3 & 4.8 & 1.4 & 84.9 & 13.0 & 1.0 & 0.5 & 0.4 & 0.2 \\
\hline Glyoxal 3 wt\% & 49.7 & 21.0 & 6.5 & 2.8 & 79.9 & 18.4 & 1.0 & 0.4 & 0.1 & 0.1 \\
\hline APS & 53.2 & 20.0 & 5.3 & 1.5 & 80.0 & 16.5 & 1.6 & 1.5 & 0.3 & 0.2 \\
\hline DMDHEU & 56.2 & 18.8 & 6.2 & 1.7 & 82.9 & 15.6 & 0.8 & 0.2 & 0.4 & 0.1 \\
\hline
\end{tabular}


Regarding the APS treatment, the increasing presence of Si-O-C suggests that the hydrolyzed siloxanes have reacted with hydroxyl functionalities of the fibre. Furthermore, unprotonated nitrogen atoms, part of the APS molecule, are discovered on the surface.

\section{Conclusions}

This paper describes the effect of different chemical treatments on the mechanical properties of technical flax fibers. The experimental data lead to the conclusion that an aqueous 3 wt\% glyoxal treatment increases the modulus of the technical fiber to the level of the elementary fibre stiffness. The stiffening effect is induced by acetal and diester cross-link formation with polyosic molecules (pectin, hemicellulose) in the amorphous interphase between elementary fibres. Shearing deformation of the amorphous interphase is expected to apparently reduce the tensile stiffness of technical fibres measured using single fibre tests rather than impregnated bundle back-calculation.

FTIR spectroscopy on concentrated glyoxal treatments detected increased amounts of ester bond formation. Furthermore, XPS showed an increase of acetal and ester functionalities on the surface of the glyoxal (3 wt\%) treated fibers, as evidence of the partial and full cross-linking reaction. ${ }^{13} \mathrm{C}$ NMR revealed that neither the crystal structure nor the degree of crystallinity of cellulose in the fibers are altered when they are subjected to this treatment. 


\section{Acknowledgements}

The author kindly acknowledges the contribution from Université Catholique de Louvain-la-Neuve (UCL) for the performance of the XPS measurements and from the Toray Chair to assist in the funding of this research.

\section{References}

1. F. Bensadoun, I. Verpoest, J. Baets, J. Mussig, N. Graupner, P. Davies, M. Gomina, A. Kervoelen and C. Baley, "Impregnated fibre bundle test for natural fibres used in composites", Journal of Reinforced Plastics and Composites, pp.116, 2017.

2. J. Gassan and A.K. Bledzki, "Thermal degradation of flax and jute fibers," Journal of Applied Polymer Science, vol. 82, pp. 1417-1422, 2001.

3. C.P.L. Chow, X.S. Xing and R.K.Y. Li, "Moisture absorption studies of sisal fibre reinforced polypropylene composites.", Composite Science and Technology, vol. 67, pp.306-313, 2006

4. A. C. de Albuquerque, K. Joseph, L. H. de Carvalho and J. R. M. d'Almeida, "Effect of Wettability and Ageing Conditions on the Physical and Mechanical Properties of Uniaxially Oriented Jute-Roving-Reinforced Polyester Composites", Composite Science and Technology, vol. 60, no. 6, pp. 833-840, 2000.

5. A. Le Duigou, P. Davies and C. Baley, "Seawater ageing of flax/poly(lactic acid) biocomposites.", Polymer Degradation and stability, vol. 94, no.7, pp. 11511162, 2009.

6. S. H. Aziz and M. P. Ansell, "The Effect of Alkalization and Fibre Alignment on the Mechanical and Thermal Properties of Kenaf and Hemp Bast Fibre Composites: Part 1 - Polyester Resin Matrix", Composite Science and Technology, vol. 64, no. 9, pp. 1219-1228, 2004.

7. A. A. Kafi, K. Magniez, en B. L. Fox, "A surface-property relationship of atmospheric plasma treated jute composites", Composites Science and Technology, vol. 71, nr. 15, pp. 1692-1698, 2011.

8. J. Gassan and A.K. Bledzki, "Possibilities for Improving the Mechanical Properties of Jute Epoxy Composites by Alkali Treatment of Fibres", Composite Science and Technology, vol.59, no.9, pp.1303-1310, 2003.

9. I. Van de Weyenberg, T. C. Truong, B. Vangrimde and I. Verpoest, "Improving the properties of $\{U D\}$ flax fibre reinforced composites by applying an alkaline fibre treatment." Composites Part A - Applied Science and Manufacturing, vol. 37, no. 9, pp. 1368 - 1376, 2006.

10. M. A. Sawpan, K. L. Pickering and A. Fernyhough, "Effect of fibre treatments on interfacial shear strength of hemp fibre reinforced polylactide and unsaturated 
polyester composites," Composites Part A - Applied Science and Manufacturing, vol. 42, no. 9, pp. 1189 - 1196, 2011.

11. Hammond, Jones, Inventory of Carbon and Energy (ICE), University of Bath, 2008.

12. A.K. Bledzki and J. Gassan, "Einfluß von haftvermittlern auf das feuchteverhalten naturfaserverstärkter kunststoffe," Die Angewandte Makromolekulare Chemie, vol. 236, no. 1, pp. 129-138,1996.

13. M. Sreekala, M. Kumaran, and S. Thomas, "Oil palm fibres: Morphology, chemical composition, surface modification and mechanical properties," Journal of Applied Polymer Science, vol. 66, pp.821-835, 1997.

14. M. Kostic, B. Pejic and P. Skundric, "Quality of chemicallly modified hemp fibres," Bioresource Technology, vol.99, no.1, pp. 94-99, 2008.

15. D. Nelson and M. Cox, Lehninger Principles of Biochemistry., third edition, W.H.Freeman \& Co Ltd, New York, 2000.

16. M. A. S. Azizi Samir, F. Alloin, and A. Dufresne, "Review of recent research into cellulosic whiskers, their properties and their application in nanocomposite field," Biomacromolecules, vol. 6, no. 2, pp. 612-626, 2005.

17. J. Müssig and C. Stevens, Industrial Applications of Natural Fibres: Structure, Properties and Technical Applications. Wiley Series in Renewable Resource, Wiley, 2010.

18. S. Deblois and J. Wiegel, Microbial and Plant Opportunities to improve Lignocellulose Utilization by Ruminants, ch. Hemicellulose in lignocellulose degradation, pp. 275-287, Elsevier, 1990.

19. N. Lavoine, I. Desloges, A. Dufresne, and J. Bras, "Microfibrillated cellulose - its barrier properties and applications in cellulosic materials: A review," Carbohydrate Polymers, vol. 90, no. 2, pp. 735 - 764, 2012.

20. K. Charlet et al., "Multi-scale morphological characterization of flax: from the stems to the fibrils," Carbohydrate Polymers, vol. 82, no. 1, pp. 54 - 61, 2010.

21. K. Charlet and A. Beakou, "Mechanical properties of interfaces within a flax bundle - Part I: Experimental analysis," International Journal of Adhesion and Adhesives, vol. 31, pp. 875-881, 2011.

22. R. Rowell, J. Han and J. Rowell, Natural polymers and agrofibers based composites: section II, agrofibers composites, ch. Characterization and factors affecting fiber properties, pp. 115-134, São Carlos: Embrapa Instrumentação Agropecuária, 2000.

23. V. Bossuyt, "Etude de la structure et des propriétés mécaniques de la fibre de lin.", PhD thesis, France, 1941.

24. D. Ruys, A. Crosky and W. Evans, "Natural bast fibre structure," International Journal of Materials \& Product Technology, vol. 17, no. 1-2, p. 2, 2002.

25. C. Baley, "Analysis of the flax fibres tensile behaviour and analysis of the tensile stiffness increase," Composites Part A - Applied Science and Manufacturing, vol. 33, no. 7, pp. 939-948, 2002.

26. S. Eichhorn et al., "Review: Current international research into cellulosic fibres and composites." Journal of Materials Science, vol. 36, no. 9, pp. 2107-2131, 2001. 
27. H. Fink, D. Hofmann and H. Purz, "On the fibrillar structure of native cellulose," Acta Polymerica, vol. 41, pp. 131-137, 1990.

28. S. Batra, Handbook of fibre science and technology. Fibre Chemistry, ch. Other long vegetable fibers, pp. 505-575, Marcel Dekker, 1998.

29. K. Charlet, "Contribution à l'étude de composites unidirectionnels renforcés par des fibres de lin: relation entre la microstructure de la fibre et ses propriétés mécaniques.", PhD thesis, University of Caen, France, 2008.

30. H. Bos and A. Donald, "In situ ESEM study of the deformation of elementary flax fibres," Journal of Materials Science, vol. 34, pp. 3029-3034, 1999.

31. K. Oksman, "High quality flax fibre composites manufactured by the resin transfer moulding process." Journal of Reinforced Plastics and Composites, vol. 20, no. 7, pp. 621-627, 2001.

32. K. Charlet et al., "Characteristics of hermès flax fibres as a function of their location in the stem and properties of the derived unidirectional composites." Composites Part A: Applied Science and Manufacturing, vol. 38, no. 8, pp. 1912 - 1921, 2007.

33. K. Charlet et al., "Mechanical Properties of Flax Fibers and of the Derived Unidirectional Composites.", Journal of Composite Materials, vol. 44, pp. 28872896, 2010.

34. V. Placet, O. Cissé and M. L. Boubakar, "Non-linear tensile behaviour of elementary hemp fibres. part i: Investigation of the possible origins using repeated progressive loading with in situ microscopic observations," Composites Part A: Applied Science and Manufacturing, vol. 56, pp. 319 - 327, 2014.

35. K. Charlet et al., "Tensile deformation of a flax fiber," Procedia Engineering, vol. 1, no. 1, pp. 233 - 236, 2009.

36. S. Alix, L. Lebrun, S. Marais, E. Philippe, A. Bourmaud, C. Baley, and C. Morvan, "Pectinase treatments on technical fibres of flax: Effects on water sorption and mechanical properties," Carbohydrate Polymers, vol. 87, pp. 177- 185, 2012.

37. D. Depuydt, K. Hendrickx, W. Biesmans, J. Ivens and A.W. Van Vuure, "Digital image correlation as a strain measurement technique for fibre tensile tests", Composites Part A: Applied Science and Manufacturing, vol. 99, pp. 76-83, 2017.

38. N. Defoirdt, S. Biswas, L. De Vriese, L.Q.N. Tran, J.V. Acker, Q. Ahsan, L. Gorbatikh, A.W. Van Vuure and I. Verpoest, "Assessment of the tensile properties of coir, bamboo and jute fibre.", Composites Part A: Applied Science and Manufacturing, vol. 41, pp. 588-595, 2010.

39. N. E. Zafeiropoulos, P. E. Vickers, C. A. Baillie and J. F. Watts, "An experimental investigation of modified and unmodified flax fibres with XPS, ToF-SIMS and ATR-FTIR", Journal of Materials Science, vol. 38, nr. 19, pp. 3903-3914, 2003.

40. S. Eichhorn, C. Baillie, N. Zafeiropoulos, L. Mwaikambo, M. Ansell, A. Dufresne, K. Entwistle, P. Herrera-Franco, G. Escamilla, L. Groom, M. Hughes, C. Hill, T. Rials and P. Wild, "Review: Current international research into cellulosic fibres and composites," Journal of Materials Science, vol. 36, no. 9, pp. 2107-2131, 2001. 
41. H. Zhao, J. H. Kwak, Z. C. Zhang, H. M. Brown, B. W. Arey and J. E. Holladay, "Studying cellulose fiber structure by SEM, XRD, NMR and acid hydrolysis," Carbohydrate Polymers, vol. 68, no. 2, pp. 235 - 241, 2007. 